Research Article

\title{
Acupuncture at Back-Shu and Front-Mu Acupoints Prevents Gastric Ulcer by Regulating the TLR4/MyD88/NF- $\kappa$ B Signaling Pathway
}

\author{
Li Li $\mathbb{D}^{1,2}$ Hao Zang ${ }^{10},{ }^{2}$ Yang Jiang, ${ }^{1}$ Yue Zhang, ${ }^{3}$ Shuangshuang Mu, ${ }^{3}$ Jiazhen Cao, ${ }^{1}$ \\ Ying $Q{ }^{4},{ }^{4}$ Zhaohui Wang $\left(\mathbb{\infty},{ }^{1}\right.$ and Wei Qi $\oplus^{5}$ \\ ${ }^{1}$ School of Acupuncture-Moxibustion and Tuina, Changchun University of Chinese Medicine, Changchun 130117, Jilin, China \\ ${ }^{2}$ School of Pharmacy and Medicine, Tonghua Normal University, Tonghua 134002, Jilin, China \\ ${ }^{3}$ College of Pharmacy, Changchun University of Chinese Medicine, Changchun 130117, Jilin, China \\ ${ }^{4}$ Wuhan Servicebio Technology Co., Ltd., Wuhan 430200, Hubei, China \\ ${ }^{5}$ Bao'an Authentic TCM Therapy Hospital, Shenzhen 518101, Guangdong, China
}

Correspondence should be addressed to Zhaohui Wang; wzhqiwei@126.com and Wei Qi; qiwei0802@126.com

Received 30 May 2020; Revised 30 January 2021; Accepted 2 February 2021; Published 9 February 2021

Academic Editor: Francesca Mancianti

Copyright $@ 2021 \mathrm{Li} \mathrm{Li}$ et al. This is an open access article distributed under the Creative Commons Attribution License, which permits unrestricted use, distribution, and reproduction in any medium, provided the original work is properly cited.

\begin{abstract}
Purpose. To assess the preventive effects of acupuncture at back-shu and front-mu acupoints on rats with restraint waterimmersion stress (RWIS)-induced gastric ulcer. Methods. Thirty-six rats were randomly divided into four groups for 10 days of treatment as follows: the normal group received no treatment; the model group received RWIS-induced gastric ulcer; the omeprazole group was administered omeprazole orally every 2 days; and the electroacupuncture group received electroacupuncture at the RN12 and BL21 acupoints every 2 days. After 10 days of treatment, except for the normal group, all rats were induced with gastric ulcer by RWIS for $3 \mathrm{~h}$. The ulcer index (UI), ulcer inhibition rate, and histopathological score were calculated. We determined the levels of tumor necrosis factor (TNF)- $\alpha$ and interleukin (IL)- 6 in serum, and the activities of myeloperoxidase (MPO), malondialdehyde (MDA), superoxide dismutase (SOD), nitric oxide (NO), and glutathione peroxidase (GSH-Px) in serum and gastric tissues. Protein expression of MyD88, nuclear factor (NF)- $\kappa$ B (p65), and toll-like receptor (TLR) 4 was quantified in gastric tissues. Results. The electroacupuncture and omeprazole groups were equivalent in terms of UI, ulcer inhibition rate, and histopathological score. The serum levels of TNF- $\alpha$ and IL- 6 were significantly lower in the electroacupuncture group compared with the omeprazole group $(P<0.05)$. Compared with the model group, there were significant changes in the levels of NO, MPO, GSH-Px, and MDA in all other groups, while the expression of TLR4, MyD88, and NF- $\kappa$ B p65 in gastric tissue decreased significantly in the electroacupuncture group. The expression of TLR4 was substantially lower in the electroacupuncture group compared with the omeprazole group. Conclusion. Acupuncture at back-shu and front-mu acupoints played a role in preventing gastric ulcer by inhibiting extracellular signals, stimulating kinases in serum and gastric tissues, and activating the inhibition of the TLR4 signaling pathway.
\end{abstract}

\section{Introduction}

Gastric ulcer is one of the most common digestive diseases but is not easily cured; those that are cured commonly reoccur. The main causes of this illness are excessive psychological stress, alcohol consumption, smoking, Helicobacter pylori infection, nutritional deficiencies, and frequent use of nonsteroidal anti-inflammatory drugs [1].
When homeostasis is disrupted, the adaptive physiological stress response occurs as a mechanism to restore the steady state. Injury to organs and diseases including diabetes can be induced by chronic or severe stress. A classic example of organ injury caused by surgery, trauma, or sepsis is stressinduced gastric ulcer [2]. These ulcers are common in critically ill patients, in whom they cause high mortality [3-6], but they are also common in patients with milder 
conditions and can affect quality of life $[7,8]$. How to treat stress ulcer and its complications remains a difficult clinical question [9].

Although the precise pathogenesis remains unknown, it is generally acknowledged that stress ulcer development involves the effects of inflammatory responses and oxidation imbalance, the upregulation of proinflammatory cytokines such as tumor necrosis factor (TNF)- $\alpha$ and interleukin (IL)6 , and the generation of reactive oxygen species (ROS) such as hydrogen peroxide $\left(\mathrm{H}_{2} \mathrm{O}_{2}\right)$, hydroxyl radical, and superoxide anion. ROS generated by ischemic tissue are considered to be a mediator of stress-induced lesions [10]. ROS induce lipid peroxidation, which subsequently leads to loss of membrane fluidity, weakened membrane integrity, and eventually the loss of cellular functions.

Many chemically synthesized drugs can be used to cure and control gastric ulcers and associated issues, but none are specific for stress ulcers; moreover, they have many adverse effects that can cause more complications. Therefore, it is urgent that we find alternative therapies that are safer and more effective for stress ulcers.

In line with the theory of traditional Chinese medicine, the use of acupuncture at back-shu and front-mu acupoints is a common clinical method. RN12 and BL21 specifically correspond to the pregastric mu and posterior gastric shu acupoints, respectively. Back-shu acupoints are distributed in the waist and back and are used to treat yang (dorsal) imbalances; front-mu acupoints are distributed in the abdomen and chest, lie adjacent to internal organs, and are used to treat yin (ventral) imbalances. The distribution of these acupoints on both sides of the body corresponds to the anatomical location of the internal organs, forming relationships between groups of front-mu and back-shu acupoints [11]. It has been proven that the combination of the RN12 and BL21 acupoints is useful for treating gastric diseases in clinical practice, possibly achieved by regulating gastric movement [12], which is closely associated with the neuroendocrine-immune network [13]. However, the protective mechanism of acupuncture at RN12 and BL21 in the treatment of stress ulcers is unclear. The purposes of this research were to understand the role of acupuncture against stress ulcers in rats and to clarify the protective mechanism of acupuncture in general.

\section{Materials and Methods}

2.1. Animals. Adult male Wistar rats (weight range, 180-200 g) were obtained from Liaoning Changsheng Biotechnology Co., Ltd. (Liaoning, China). We adopted all animalrelated policies as described in the guidelines of Changchun University of Chinese Medicine regarding the use of experimental animals. The animals were bred with free access to water and housed under a 12-hour light-dark cycle with a relative humidity of $55 \pm 5 \%$ at a room temperature of $25 \pm 3^{\circ} \mathrm{C}$.

2.2. Animal Treatment. The 36 rats were randomly divided into four groups of 9 rats each: normal group (untreated), model group (gastric ulcer induction with restraint plus water-immersion stress (RWIS)), omeprazole group (pretreatment with omeprazole before gastric ulcer induction), and electroacupuncture group (pretreatment with electroacupuncture before gastric ulcer induction). All experiments ran for 10 days. The groups were treated as follows: (1) normal group rats and model group rats were raised in a routine manner; (2) omeprazole group rats were given omeprazole $(20 \mathrm{mg} / \mathrm{kg})$ by gavage every 2 days; and (3) electroacupuncture group rats received electroacupuncture $(2 \mathrm{~Hz})$ for $10 \mathrm{~min}$ every 2 days. For the localization of acupuncture points in rats (Figure 1), we utilized a positioning method based on the corresponding anatomical structures in humans, as described previously [11]. The rats were anesthetized using a small animal anesthesia machine before administering electroacupuncture using acupuncture needles (Huatuo, Jiangsu, China) inserted into the acupoints corresponding to back-shu BL21 and front-mu RN12 in humans. These needles were connected to an electronic acupuncture instrument (SDZ-V apparatus, Huatuo, Jiangsu, China).

2.3. RWIS-Induced Gastric Ulcer Modeling. The procedure employed to induce gastric stress ulcer was previously described [14]. We aimed to minimize suffering and prevent death by drowning while carrying out this modeling. All rats except for those in the normal group were deprived of food for $48 \mathrm{~h}$ before modeling and were allowed to drink water freely throughout the process. The rats were placed in wirerestraint cages and immersed in a water bath up to the level of the xiphoid process for $3 \mathrm{~h}$ at a temperature of $22 \pm 1^{\circ} \mathrm{C}$.

2.4. Assessment of Gastric Mucosal Damage. At the end of the RWIS, the rats were anesthetized by intraperitoneal injection of sodium pentobarbital $(30 \mathrm{mg} / \mathrm{kg})$. Blood was drawn via the abdominal aorta and settled at room temperature for $20 \mathrm{~min}$ before separation of the serum by centrifugation at $3000 \mathrm{r} / \mathrm{min}$ at $4^{\circ} \mathrm{C}$ for 15 minutes; samples were preserved at $-20^{\circ} \mathrm{C}$ until use. The stomach was removed quickly, cut along the curved side, inverted to expose the mucosal surface, and rinsed with iced sodium chloride solution. The gastric mucosal damage was evaluated macroscopically according to the Guth et al. standard [15]. The length of each lesion was measured, and the ulcer index (UI) was expressed as the amount of the length of all lesions.

For microscopic histologic examinations, the gastric tissue specimens of three rats from each group were fixed in $10 \%$ formaldehyde, dehydrated and washed, embedded by infiltration with paraffin, and sliced into $4 \mu \mathrm{m}$ thick sections. Sections were dewaxed and stained with hematoxylin and eosin. A microscopic score was assessed according to the method described previously [16]. The gastric tissues of the remaining six rats from each group were frozen in liquid nitrogen immediately after removal and stored at $-80^{\circ} \mathrm{C}$ until use.

2.5. Measurement of Oxidative Stress Index Activity in Serum and Gastric Tissues. Gastric tissue was homogenized in physiological saline (ratio: 1 part tissue to 9 parts saline), 


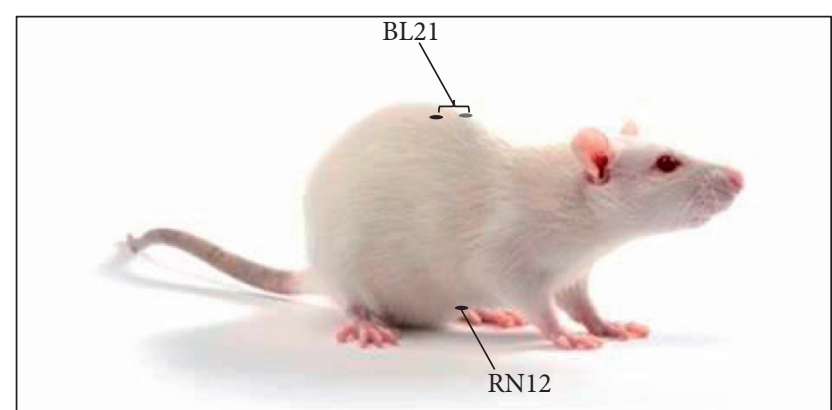

FIgURE 1: The location of the RN12 and BL21 acupoints in the rat.

then spun by centrifugation ( $4000 \mathrm{r} / \mathrm{min}$ for $10 \mathrm{~min}$ ) to obtain the supernatant. Serum and gastric tissues were evaluated for myeloperoxidase (MPO), malondialdehyde (MDA), superoxide dismutase (SOD), nitric oxide (NO), and glutathione peroxidase (GSH-Px) content using assay kits according to the manufacturer's guidelines for each (Nanjing Jiancheng, China). The protein concentration in gastric tissue was determined by the bicinchoninic acid (BCA) method and was not determined for serum samples.

2.6. Cytokine Evaluation. The levels of the cytokines TNF- $\alpha$ and IL- 6 in serum were determined using enzyme-linked immunosorbent assay kits (Thermo Fisher, America) according to the manufacturer's guidelines. The absorbance was recorded at $450 \mathrm{~nm}$ on a microplate spectrophotometer.

2.7. Western Blot Analysis. Gastric tissue was mixed with a phosphatase inhibitor cocktail, radioimmunoprecipitation assay lysis buffer, and phenylmethylsulfonyl fluoride (all from Beyotime, China), transferred to a homogenizer, homogenized in an ice bath, and then allowed to stand for $30 \mathrm{~min}$; all of the samples were subjected to centrifugation $(12000 \mathrm{~g})$ for $10 \mathrm{~min}$ at $4^{\circ} \mathrm{C}$. The total protein concentration of the supernatant was determined using a BCA kit, with bovine serum albumin as the standard. The supernatant (an equivalent amount of protein loaded for each sample) was loaded into a sodium dodecyl sulfate-polyacrylamide gel and separated by electrophoresis. The proteins were transferred to polyvinylidene fluoride membranes (Millipore, USA), blocked with $5 \%$ skim milk for $1 \mathrm{~h}$, washed 3 times in Tris-buffered saline containing $0.1 \%$ Tween 20 (TBST), and then incubated individually with the following antibodies at $4^{\circ} \mathrm{C}$ overnight: primary rabbit antibodies against nuclear factor (NF)- $\kappa \mathrm{B}$ p65 (1:1000, Servicebio, China); anti- $\beta$-actin antibody $(1: 3000$, Servicebio); antitoll-like receptor (TLR) 4 antibody (1:1000, Servicebio); and anti-MyD88 antibody (1:1000, Bioss, China). After washing with TBST, the membranes were incubated with the secondary antibody at room temperature for $1 \mathrm{~h}$. Immunoreactive bands were imaged using an enhanced chemiluminescence detection kit (Bio-Rad, USA), and Image Lab 4.1 (Bio-Rad) was applied for signal collection and densitometric image analysis.
2.8. Statistical Analysis. All results are expressed as mean\pm standard deviation. The data were analyzed using SPSS 23.0 (IBM, Armonk, NY, USA). Statistical analysis was carried out with one-way analysis of variance accompanied by Fisher's least significant difference test. The differences in mean values between the omeprazole group and the electroacupuncture group were calculated by the $t$-test. $P$ values $<0.05$ were recognized as indicating statistical significance.

\section{Results}

3.1. Electroacupuncture Prevented Stress Ulceration. As shown in Figure 2, the gastric mucosa in the normal untreated group of rats was intact and smooth, with a pale pink color. The gastric mucosa of the model group was comparatively hyperemic and less smooth, with many hemorrhagic spots of different sizes that were concentrated in the glands, with clear boundaries and no perforation. This result showed that treatment with RWIS induced dramatic gastric mucosal damage, causing obvious ulcerative lesions in the rats. In the omeprazole group, the gastric mucosa was smooth and the hemorrhagic spots were scattered. In the electroacupuncture group, the gastric mucosa was smooth and the color was lighter than any of the other groups, with the occasional observation of crater-like ulcers. This result demonstrated that pretreatment with electroacupuncture dramatically reduced the number and extent of lesions compared with the model group. Moreover, electroacupuncture showed similar effects to omeprazole.

3.2. Electroacupuncture Decreased the Gastric UI. The success rate of gastric ulcer modeling by RWIS was $100 \%$. The model group had the highest UI, which was statistically significant compared with the normal group (Table 1). The UI was lower in both the omeprazole and electroacupuncture groups compared with the model group. Furthermore, there were no significant differences in UI or ulcer inhibition rate between the electroacupuncture and omeprazole groups, demonstrating that electroacupuncture pretreatment reduced the UI and that acupuncture had the same effects as omeprazole (Table 1).

\subsection{Electroacupuncture Reduced Gastric Mucosal Tissue} Lesions. Histopathologic results are shown in Figure 3. In the normal group, the gastric mucosa was smooth and intact, with neat arrangement of epithelial cells, and no capillary blood congestion or inflammatory cell infiltration. In the model group, the mucosal epithelial structure was destroyed, with large numbers of dead mucosal epithelial cells (black arrows). We also observed contraction and deep staining of the cell nuclei, aggravated demyelination, disorderly arrangement of glands, and rupturing of submucosal blood vessels. Large numbers of red blood cells could be seen in the intercellular space, and there was inflammatory cell infiltration. Compared with the model group, the omeprazole group showed thinning of the mucosa and submucosa, and neat arrangement of glands, but the glandular cavity was 


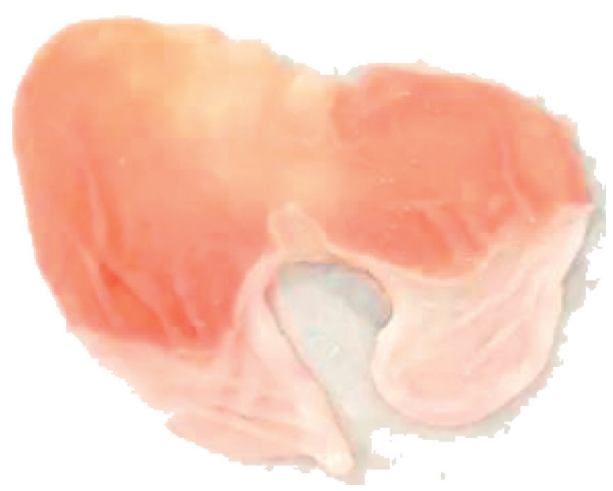

(a)

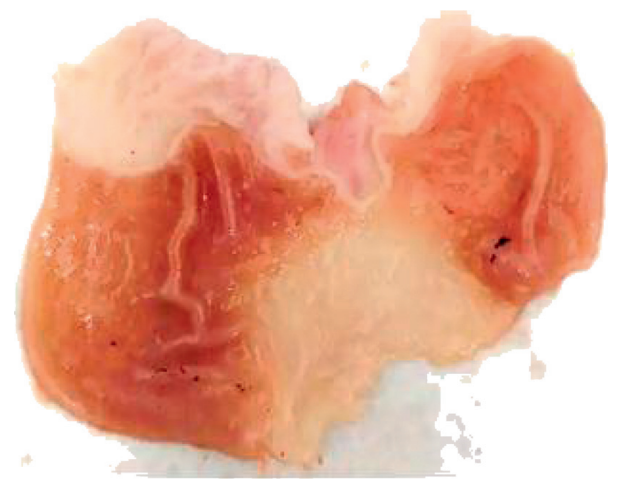

(c)

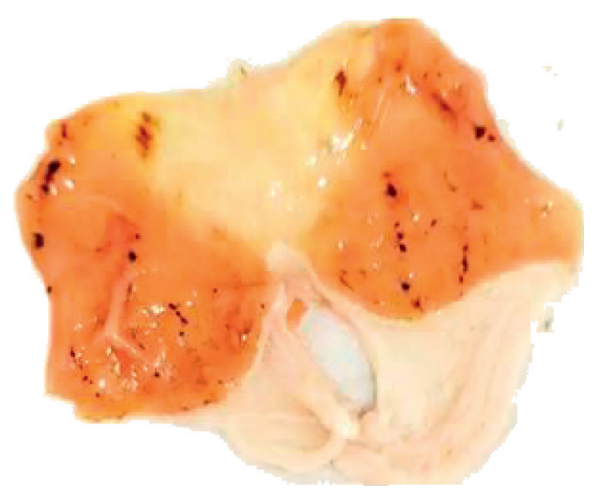

(b)

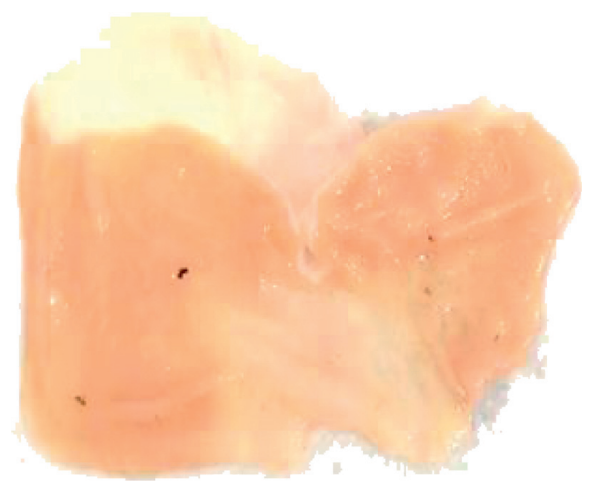

(d)

Figure 2: Macroscopic images of representative gastric tissues from each treatment group. (a) Normal. (b) Model. (c) Omeprazole. (d) Electroacupuncture.

TABLE 1: Ulcer index and ulcer inhibition rate in each group.

\begin{tabular}{lcc}
\hline Group & Ulcer index $\left(\mathrm{mm}^{2}\right)$ & $\begin{array}{c}\text { Ulcer inhibition rate } \\
(\%)\end{array}$ \\
\hline Normal & - & - \\
Model & $10.17 \pm 1.77^{\mathrm{a}}$ & $67.21 \%$ \\
Omeprazole & $3.33 \pm 0.75^{\mathrm{b}}$ & $57.38 \%$ \\
Electroacupuncture & $4.33 \pm 0.75^{\mathrm{c}}$ & \\
\hline
\end{tabular}

${ }^{\mathrm{a}}$ Model group compared with the normal group $(P<0.05)$; ${ }^{\mathrm{b}}$ omeprazole group compared with the model group $(P<0.05)$; ${ }^{\mathrm{c}}$ electroacupuncture group compared with the model group $(P<0.05)$.

slightly larger and there was minor infiltration of inflammatory cells (green arrows). In the electroacupuncture group, the gastric mucosal surface was comparatively less damaged, with different degrees of repair and hyperplasia (red arrows). We also observed shedding of epithelial cells in the omeprazole and electroacupuncture groups, and there was less inflammatory cell infiltration compared with the model group. Interestingly, preacupuncture treatment successfully improved the pathological features by decreasing congestion and tissue inflammation, consequently reducing the pathological scores.

Histopathological examination scoring (Figure 4) showed that the model group had the highest lesion score, with a significant difference compared with the normal group. Both the omeprazole group and the electroacupuncture group had significantly lower lesion scores than the model group.
3.4. Electroacupuncture Reduced the Level of Peroxide in Serum and Gastric Tissues. Compared with the normal group, there was increased MDA activity in the serum and gastric tissues of the other three groups, demonstrating that the oxidative damage caused by stress ulcer induction is obvious (Figure 5). Compared with the model group, there was lower MDA activity in the serum and gastric tissues in the electroacupuncture and omeprazole groups, with the decline being more obvious in the gastric tissue. At the same time, the levels of GSH-Px and NO increased significantly. The GSH-Px content was lower in the electroacupuncture group compared with the omeprazole group, but there was no significant difference between the two in NO content.

Compared with the normal group, the MPO content of the model group increased significantly. Compared with the model group, in the electroacupuncture group, the MPO content was significantly lower in the serum and gastric tissues, while the content of MPO decreased significantly only in the gastric tissue in the omeprazole group. Conversely, the levels of SOD in the serum and gastric tissues of both the omeprazole and electroacupuncture groups showed an increasing trend. These results demonstrated that electroacupuncture and omeprazole inhibited the oxidative damage of stress ulceration to an obvious degree and that the effects were specific.

3.5. Electroacupuncture Reduced the Expression of Serum Inflammatory Factors. As shown in Figure 6, the expression of IL- 6 and TNF- $\alpha$ in serum in the three induced stress ulcer 


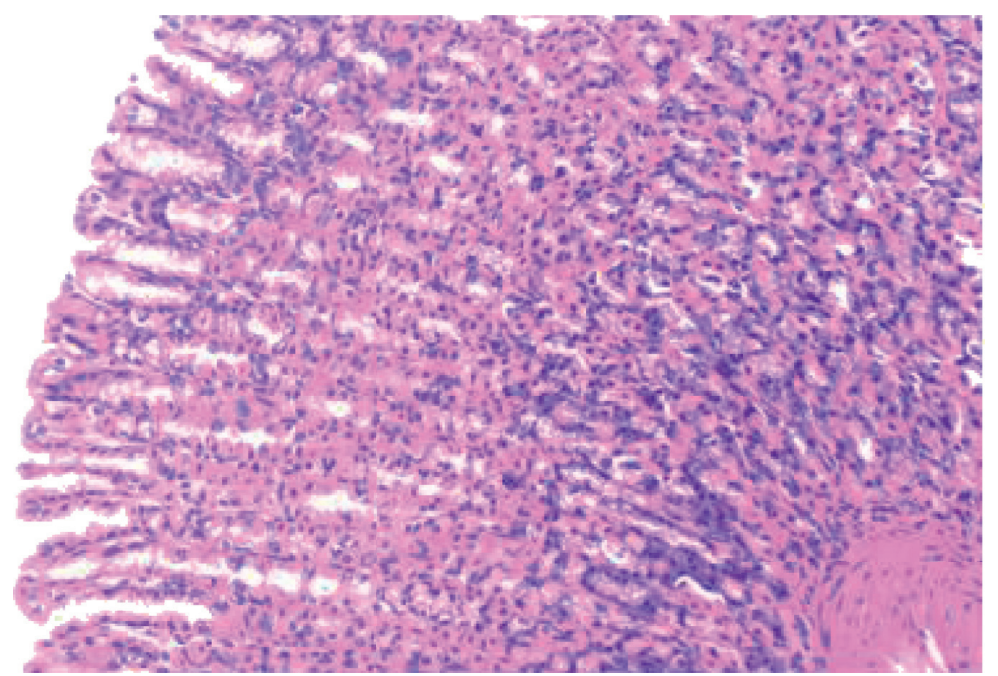

(a)

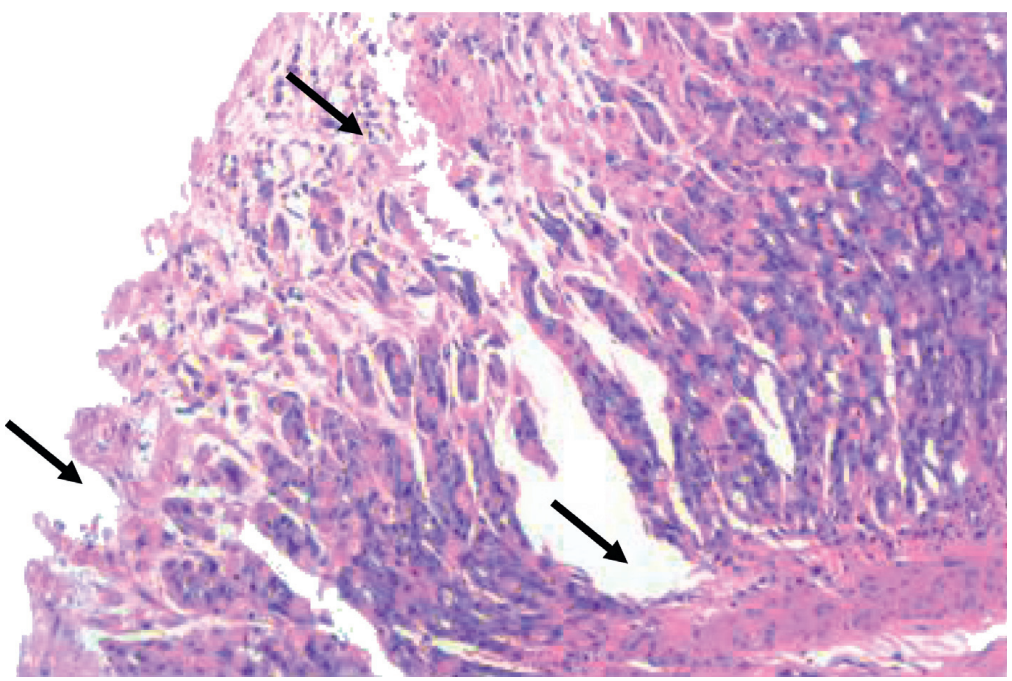

(b)

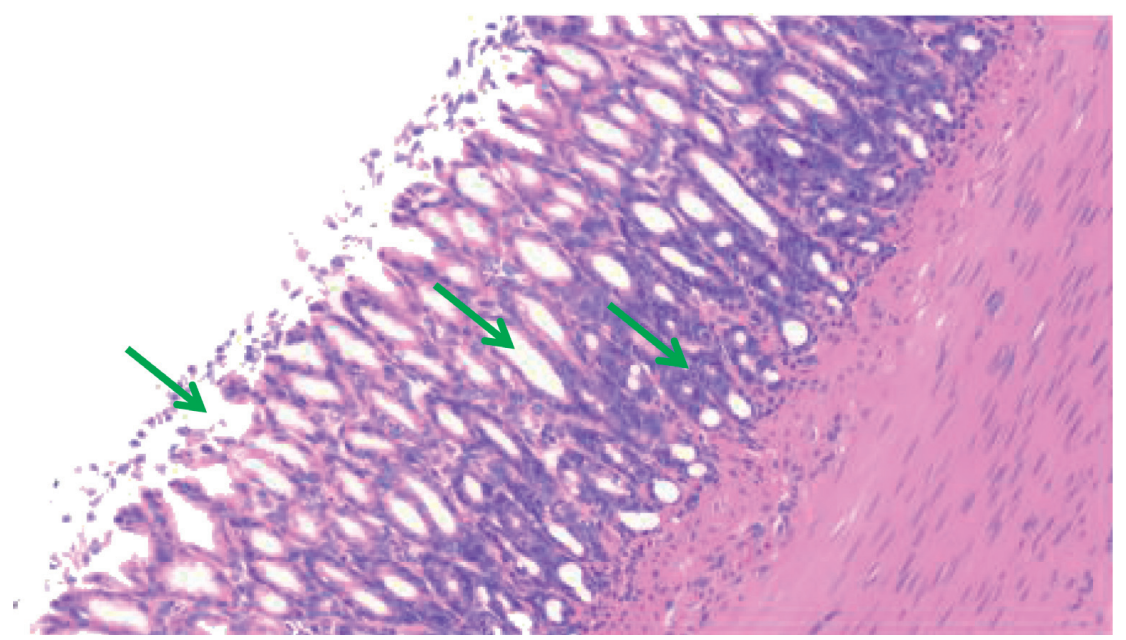

(c)

Figure 3: Continued. 


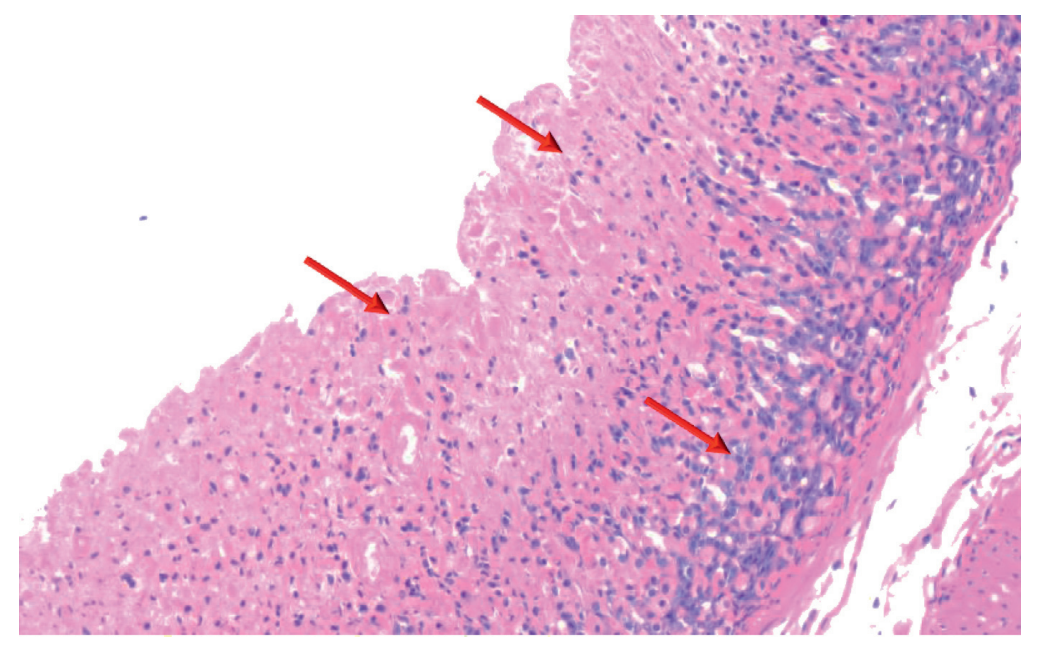

(d)

Figure 3: Representative histopathological photos of gastric tissue sections from each group. (a) Normal. (b) Model. (c) Omeprazole. (d) Electroacupuncture.

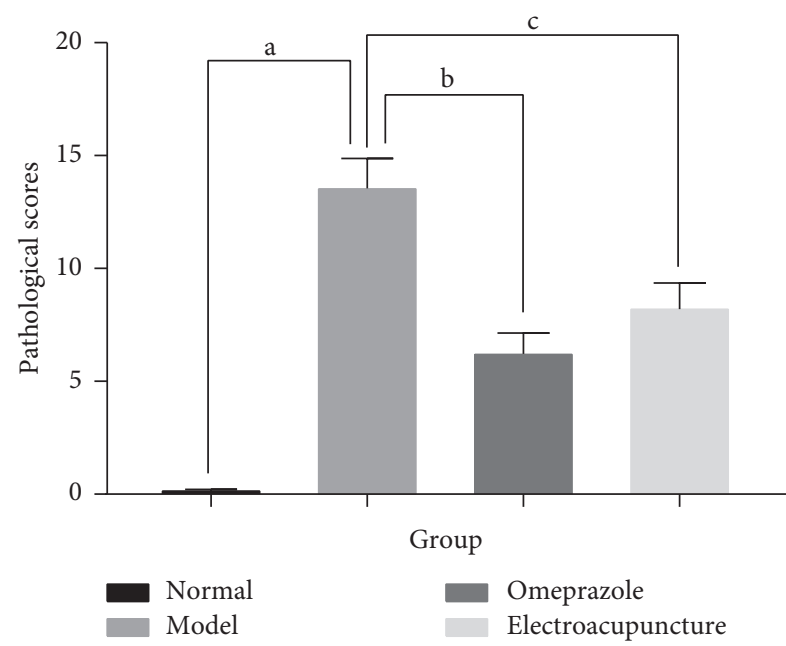

FIGURE 4: Histopathological lesion scores in each group. ${ }^{\text {a }}$ Model group compared with the normal group $(P<0.05)$; ${ }^{b}$ omeprazole group compared with the model group $(P<0.05)$; ' electroacupuncture group compared with the model group $(P<0.05)$.

groups was increased compared with the normal group, indicating that overexpression of inflammatory factors occurs during gastric mucosal injury. Compared with the model group, however, the expression of IL-6 and TNF- $\alpha$ in serum was markedly reduced in the electroacupuncture and omeprazole groups, suggesting that electroacupuncture and omeprazole can reduce the expression of related inflammatory factors in serum. The electroacupuncture group also had significantly reduced expression of TNF- $\alpha$ compared with the omeprazole group, further suggesting that pretreatment with electroacupuncture has an obvious inhibitory effect on the inflammatory response induced by stress ulcer.

3.6. Electroacupuncture Inhibited the Protein Expression of TLR4, MyD88, and NF- $\kappa B$ p65. The expression levels of TLR4, MyD88, and NF- $\kappa \mathrm{B}$ (p65) proteins in gastric tissue in the model group were dramatically increased compared with the normal group (Figure 7 and Table 2). These proteins showed decreased expression in the omeprazole and electroacupuncture groups compared with the model group. Expression of TLR4 and MyD88 was significantly reduced in the electroacupuncture group compared with the omeprazole group, indicating that the preventive effect of electroacupuncture on stress ulcers may be exerted specifically via suppression of the TLR4/NF- $\kappa \mathrm{B}$ signaling pathway.

\section{Discussion}

This study showed that electroacupuncture prevented stress ulcers with effects that were comparable to those of omeprazole treatment in rats. Electroacupuncture and omeprazole may prevent stress ulcers through a combination of antioxidant and anti-inflammatory actions, and by inhibition of the TLR4/MyD88/NF- $\kappa$ B signaling pathway.

At present, there is no satisfactory treatment for stress ulcers. Stress ulcer prophylaxis [17] is recommended, most commonly with proton pump inhibitors (PPIs) and type II histamine receptor antagonists [18]. However, the use of PPIs may increase the chance of nosocomial pneumonia, Clostridium difficile infections, and cardiovascular events [19].

Acupuncture is a safe treatment method with minimal impact on the environment. Electroacupuncture has been proven to relieve multiple stress-induced conditions, including irregular gastric rhythm, abnormal defecation, delayed gastric emptying, and anxiolytic-like behavioral effects [20-22]. Electroacupuncture is widely used in various gastrointestinal diseases by anti-inflammatory mechanism $[23,24]$.

Studies have described multiple protective mechanisms of acupuncture on gastric mucosal tissues, which include strengthening the gastric mucosal barrier, regulating gastric acid secretion and gastrointestinal hormones, improving gastric mucosal blood flow, and enhancing antagonism against free radical-induced lesions [25]. 


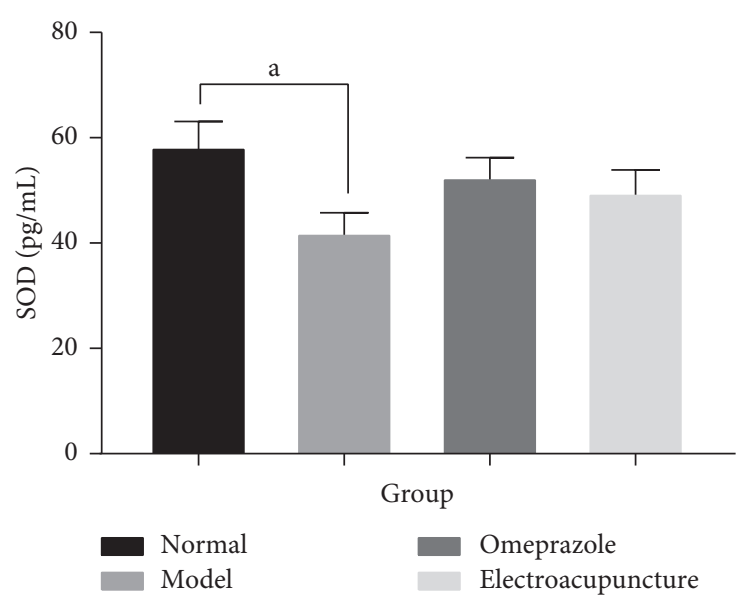

(a)

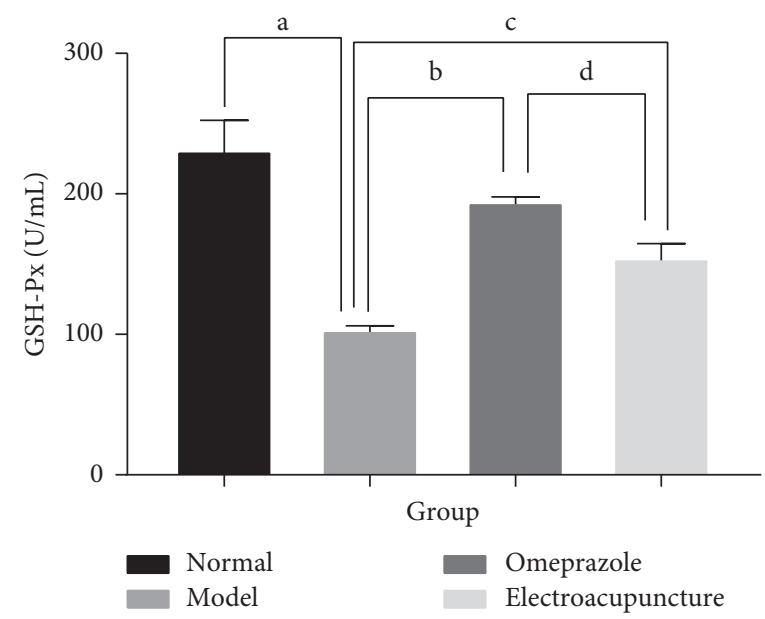

(c)

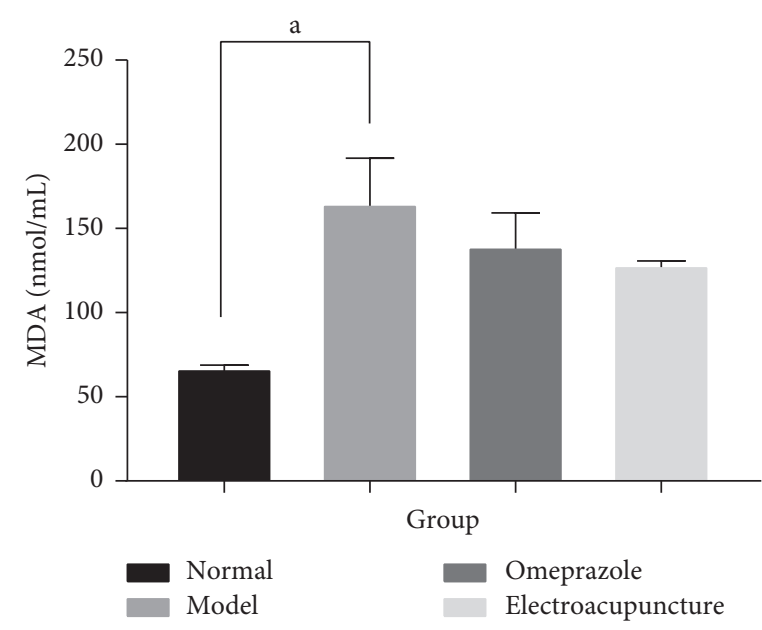

(e)

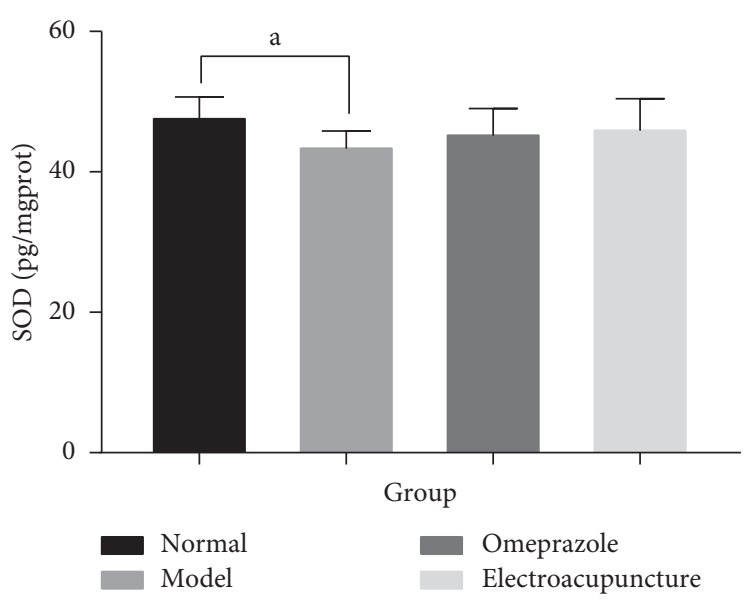

(b)

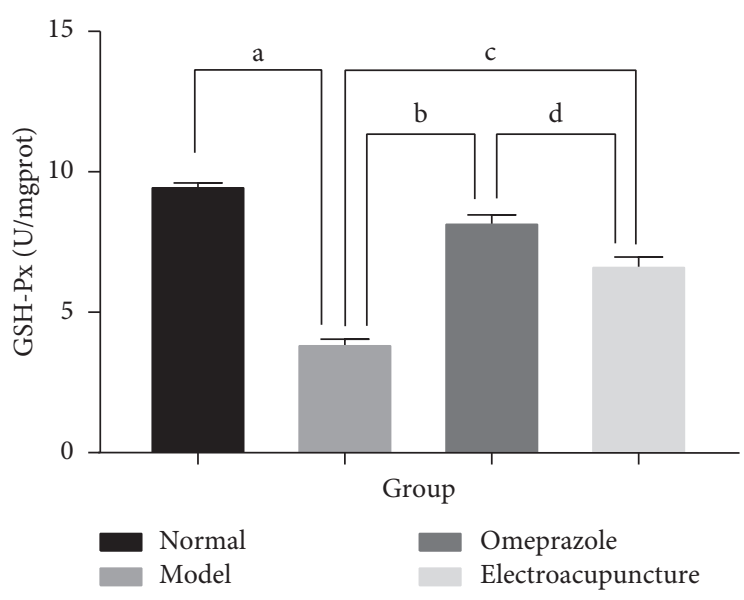

(d)

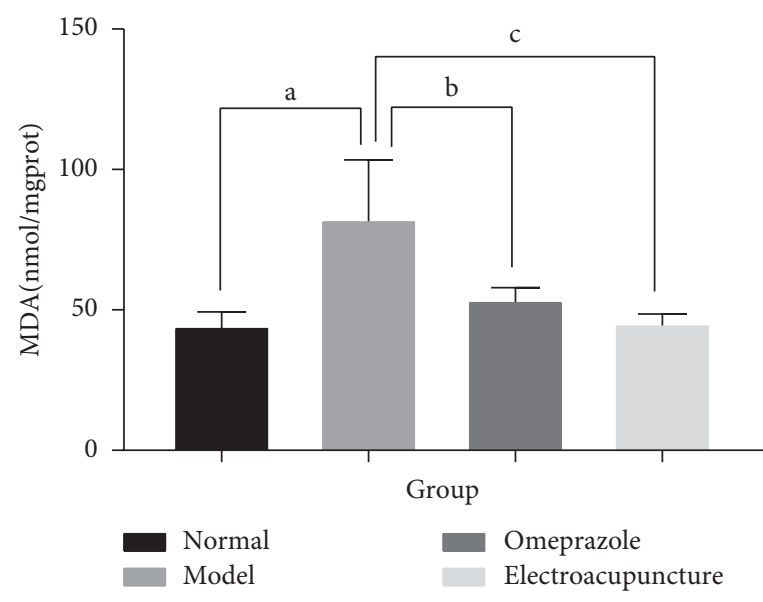

(f)

FIgURE 5: Continued. 


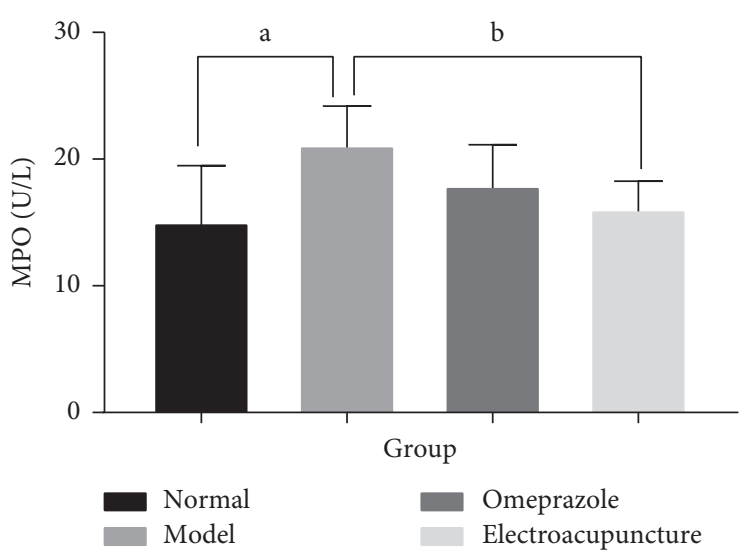

(g)

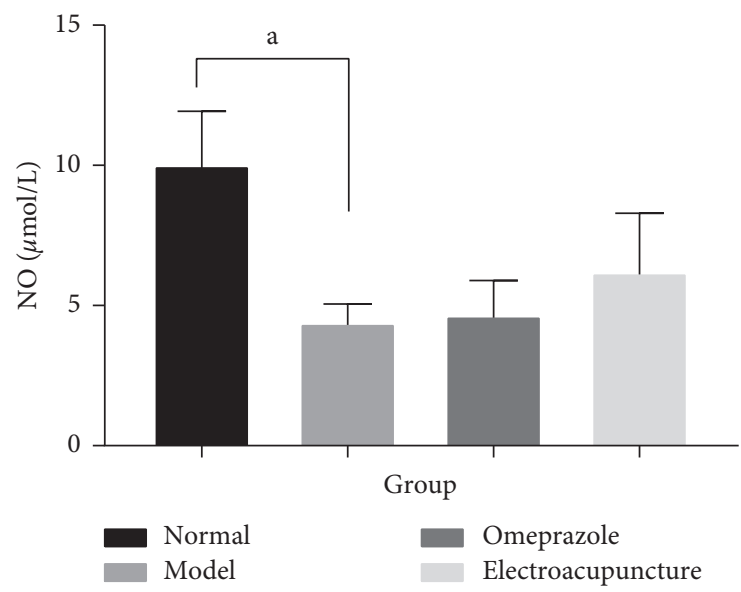

(i)

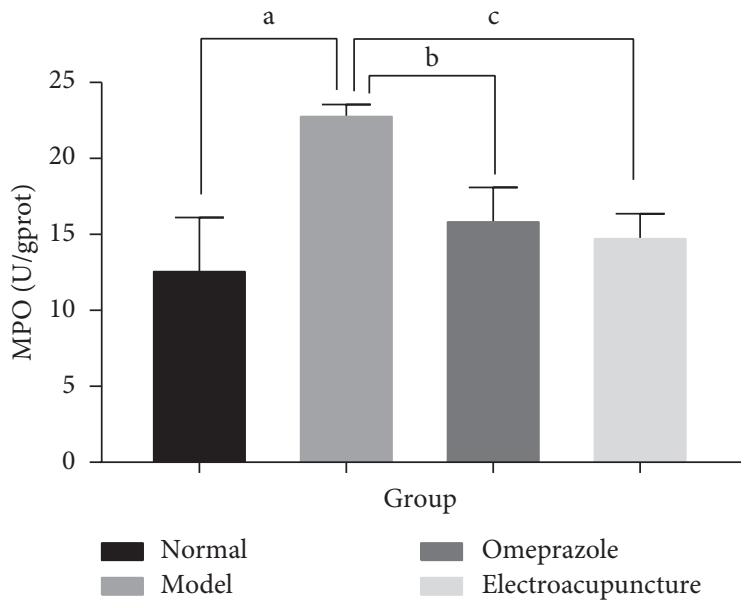

(h)

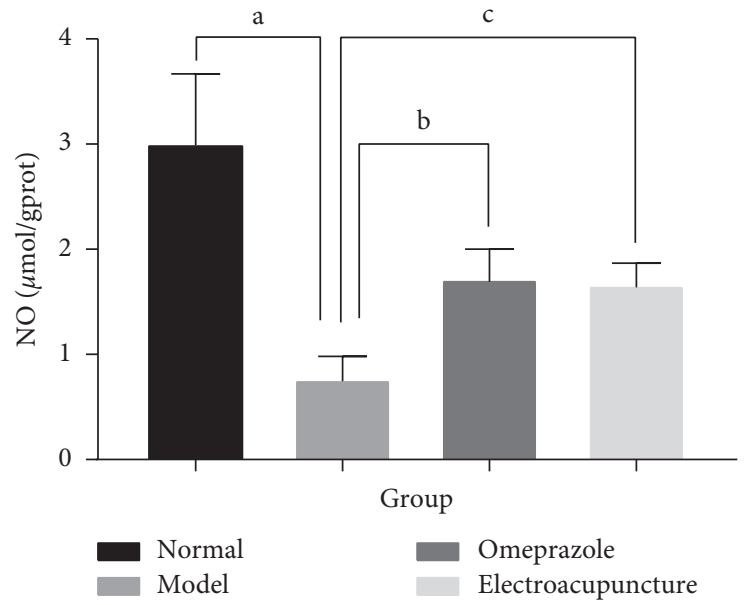

(j)

Figure 5: Levels of five oxidative stress indicators in serum (left panels) and gastric tissue (right panels) in each group. ${ }^{\mathrm{a}}$ Model group compared with the normal group $(P<0.05)$; ${ }^{\text {b }}$ omeprazole group compared with the model group $(P<0.05)$; ${ }^{c}$ electroacupuncture group compared with the model group $(P<0.05)$; electroacupuncture group compared with the omeprazole group $(P<0.05)$.

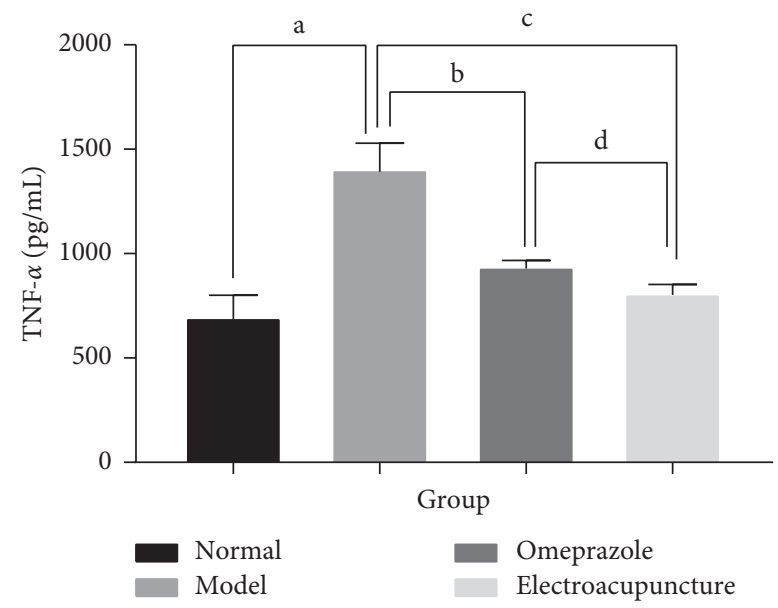

(a)

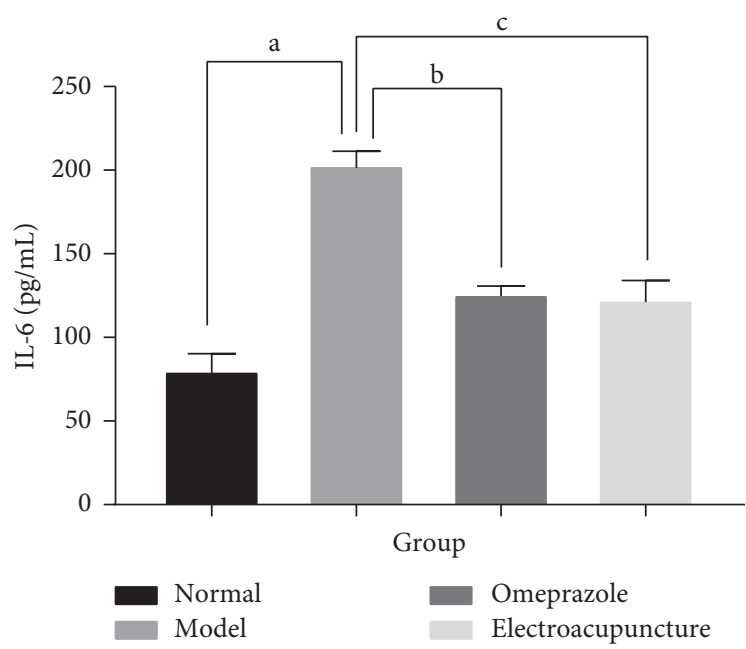

(b)

FIgURE 6: The expression of two inflammatory factors in serum in each group. ${ }^{\text {a }}$ Model group compared with the normal group $(P<0.05)$; ${ }^{\mathrm{b}}$ omeprazole group compared with the model group $(P<0.05)$; ${ }^{\mathrm{c}}$ electroacupuncture group compared with the model group $(P<0.05)$; delectroacupuncture group compared with the omeprazole group $(P<0.05)$. 


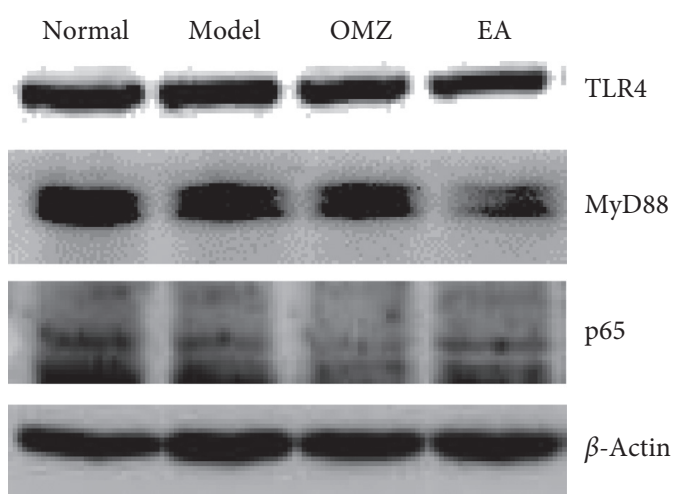

FIGURE 7: Western blotting showing representative bands of three members of the TLR4/NF- $\kappa$ B pathway in each group. Nor: normal group; Mod: model group; OMZ: omeprazole group; EA: electroacupuncture group.

TABLe 2: Protein expression of TLR4, MyD88, and NF- $\kappa$ B (p65) in the gastric tissues in each group.

\begin{tabular}{lccc}
\hline Group & TLR4 & MyD88 & NF- $\kappa \mathrm{B}(\mathrm{p} 65)$ \\
\hline Normal & $0.75 \pm 0.20$ & $0.64 \pm 0.24$ & $0.66 \pm 0.06$ \\
Model & $1.30 \pm 0.30^{\mathrm{a}}$ & $1.19 \pm 0.22^{\mathrm{a}}$ & $1.20 \pm 0.03^{\mathrm{a}}$ \\
Omeprazole & $0.88 \pm 0.19^{\mathrm{b}}$ & $0.86 \pm 0.19^{\mathrm{b}}$ & $0.77 \pm 0.06^{\mathrm{b}}$ \\
Electroacupuncture & $0.68 \pm 0.29^{\mathrm{c}, \mathrm{d}}$ & $0.77 \pm 0.21^{\mathrm{c}, \mathrm{d}}$ & $0.76 \pm 0.06^{\mathrm{c}}$ \\
\hline
\end{tabular}

${ }^{\mathrm{a}}$ Model group compared with the normal group $(P<0.05)$; ${ }^{\mathrm{b}}$ omeprazole group compared with the model group $(P<0.05)$; ${ }^{c}$ electroacupuncture group compared with the model group $(P<0.05)$; delectroacupuncture group compared with the omeprazole group $(P<0.05)$.

There is increasing evidence that ROS play a crucial role in the formation of stress ulcers [26]. ROS may cause direct tissue damage or induce downstream signaling pathways to mediate inflammatory damage.

Previous reports indicate that MDA is the main product of lipid peroxidation and a biomarker for oxidative stress. MPO is an important peroxidase expressed in neutrophils. MPO can be used not only as a quantitative measure of neutrophil numbers (as a reflection of neutrophil infiltration), but also as a quantitative reflection of the degree of inflammatory damage. NO is related to gastrointestinal mucosal injury and defense. NO supports the healthy function of the gastrointestinal mucosa and has a protective effect on cells. SOD is the main antioxidant against ROS and can effectively prevent gastrointestinal mucosal damage. GSH-Px further degrades $\mathrm{H}_{2} \mathrm{O}_{2}$ produced by SOD disproportionation [27]. The induction of stress ulcer in the model rats in this study significantly increased MDA and MPO and significantly decreased SOD, GSH-Px, and NO compared with normal, untreated rats. These results indicate that when stress ulcers occur, oxidized substances are increased, while antioxidant substances that could reduce gastric tissue damage are decreased. After pretreatment with omeprazole or electroacupuncture, SOD and NO increased and GSH-Px increased markedly in the omeprazole and electroacupuncture groups; GSH-Px was significantly higher in the omeprazole group than in the electroacupuncture group. MDA and MPO decreased, especially in gastric tissue, and there was significantly lower serum MPO in the electroacupuncture group than the model group.

Previous studies have also found that an imbalance between the production of ROS and endogenous antioxidant activity can cause oxidative stress. ROS in ulcer tissue may be derived from the infiltration of inflammatory cells [28]. Superoxide radical anions are generated by the reaction of neutrophils with lipids, eventually leading to the production of lipid peroxides [29].

Our experiments showed that the prevention of gastric ulcers induced by RWIS in rats was mainly exerted by increasing GSH-Px and decreasing MPO and MDA. Therefore, the mechanism of action of electroacupuncture in preventing gastric ulcers in rats appears to be the reduction of neutrophil infiltration and prevention of lipid peroxidation. This protective therapeutic effect was stronger in the electroacupuncture group than the omeprazole group.

Inflammation is another key mechanism that leads to the involvement of increased ROS production in gastric ulcerative injury. It is well known that gastric ulcers are the result of tissue necrosis caused by mucosal congestion. Tissue necrosis and chemokine release attract immune cells, phagocytosis of necrotic tissue, and the release of proinflammatory cytokines such as TNF- $\alpha$ and IL-6, thereby activating local endothelial cells and epithelial cells [30].

Research has shown that acupuncture can reduce TNF- $\alpha$ and IL-6 levels in serum $[31,32]$, as well as inhibit the degree of intracellular inflammatory response [33-35]. The results of our study showed that the levels of IL- 6 and TNF- $\alpha$ were significantly, markedly higher in the model group compared with the normal group, indicating that stress ulceration increases the infiltration of proinflammatory cells. IL-6 and TNF- $\alpha$ levels were significantly lower in rats pretreated with omeprazole or electroacupuncture compared with those in the model group, and TNF- $\alpha$ was further reduced in the electroacupuncture group compared with the omeprazole group $(P<0.05)$. This observation suggests that pretreatment with electroacupuncture can inhibit inflammation and protect gastric tissue by reducing the infiltration of inflammatory cells and minimizing the secretion of proinflammatory cytokines including IL- 6 and TNF- $\alpha$.

$\mathrm{NF}-\kappa \mathrm{B}$ is the main transcription factor for the regulation of inflammation. Proinflammatory factors driven by NF- $\kappa \mathrm{B}$ create a powerful signal that regulates immune cells involved in inflammation [36]. In the TLR4/MyD88 pathway, NF- $\kappa \mathrm{B}$ is a prominent downstream signaling molecule [37, 38]. MyD88 was the first member in the TLR family to be identified and is used as an adaptor by all TLRs except for TLR3; it activates NF- $\kappa \mathrm{B}$ to induce inflammatory cytokines [39]. The TLR4/MyD88/NF- $\kappa \mathrm{B}$ pathway is related to the immune response, and its activation is the key to the development of various diseases. When the signal is transferred from TLR4 to MyD88, with the continuous recruitment of IRAK4 and TRAF6, the IKK complex will be activated, causing the proteasome to destroy $\mathrm{I} \kappa \mathrm{B}$. Next, the NF- $\kappa \mathrm{B}$ p 65 subunit is allowed to translocate into the nucleus and promote the production of proinflammatory cytokines such as TNF- $\alpha$ and IL-6 [40]. Recent research indicates that both oxidative stress and infection stress can share the same TLR 
signaling pathway [41-44]. Thus, it is plausible that the pathogenesis of stress-induced gastric ulcer involves the TLR4/MyD88/NF- $\kappa$ B signal transduction pathway. Studies have reported that acupuncture exerts anti-inflammatory effects in rats with cerebral ischemia-reperfusion injury by inhibiting the TLR4/NF- $\kappa \mathrm{B}$ signaling pathway [45]. Our research showed that expression of TLR4, NF- $\kappa \mathrm{B}$, and MyD88 was significantly, markedly increased by RWIS in the model group and significantly decreased by pretreatment with electroacupuncture, indicating that preventive electroacupuncture could inhibit the activation of TLR4/NF- $\kappa \mathrm{B}$ signaling induced by stress ulcer.

\section{Conclusions}

We confirmed the protective effect of pretreatment with electroacupuncture at the back-shu and front-mu acupoints on stress-induced gastric ulcers induced by RWIS in rats. Changes in the TLRs/NF- $\kappa$ B signaling pathway revealed that acupuncture and omeprazole operate through a mechanism involving antioxidation and anti-inflammation. Acupuncture is a common clinical method for treating gastric ulcers, and our results provide a scientific basis for using acupuncture to prevent gastric ulcers.

\section{Abbreviations}

$\begin{array}{ll}\text { UI: } & \text { Ulcer index } \\ \text { IL-6: } & \text { Interleukin-6 } \\ \text { TNF- } \alpha: & \text { Tumor necrosis factor- } \alpha \\ \text { SOD: } & \text { Superoxide dismutase } \\ \text { MDA: } & \text { Malondialdehyde } \\ \text { MPO: } & \text { Myeloperoxidase } \\ \text { NO: } & \text { Nitric oxide } \\ \text { GSH-Px: } & \text { Glutathione peroxidase } \\ \text { TLR4: } & \text { Toll-like receptor } 4 \\ \text { MyD88: } & \text { Myeloid differentiation primary response gene } \\ & \text { 88 } \\ \text { NF- } \kappa \text { B: } & \text { Nuclear factor kappa B } \\ \text { IL-1 } \beta: & \text { Interleukin-1 } \beta \\ \text { ROS: } & \text { Reactive oxygen species } \\ \text { H2O2: } & \text { Hydrogen peroxide } \\ \text { OH: } & \text { Hydroxyl radical } \\ \text { BCA: } & \text { Bicinchoninic acid } \\ \text { ELISA: } & \text { Enzyme-linked immunosorbent assay } \\ \text { PMSF: } & \text { Phenylmethylsulfonyl fluoride } \\ \text { RIPA: } & \text { Radioimmunoprecipitation assay } \\ \text { SDS- } & \text { Sodium dodecyl sulfate-polyacrylamide gel } \\ \text { PAGE: } & \text { electrophoresis } \\ \text { PVDF: } & \text { Polyvinylidene fluoride } \\ \text { TBST: } & \text { Tris-buffered saline Tween } \\ \text { ANOVA: } & \text { Analysis of variance } \\ \text { LSD: } & \text { Least significant difference } \\ \text { SUP: } & \text { Stress ulcer prophylaxis } \\ \text { PPI: } & \text { Proton pump inhibitor } \\ \text { IRAK4: } & \text { Interleukin-1 receptor-associated kinase } 4 \\ \text { TRAF6: } & \text { TNF receptor-associated factor } 6 \\ \text { IKK: } & \text { I } \kappa \text { B kinase } \\ \text { I } \kappa \text { B: } & \text { Inhibitor of NF- } \kappa \text { B. } \\ & \\ & \\ & \end{array}$

\section{Data Availability}

The data used to support the findings of this study are included within the study and available from the corresponding author upon request.

\section{Conflicts of Interest}

The authors declare no conflicts of interest.

\section{Authors' Contributions}

$\mathrm{Li} \mathrm{Li}$, Yang Jiang, and Yue Zhang contributed to the design of the work, data collection, analysis, and interpretation of the data. Shuangshuang $\mathrm{Mu}$, Jiazhen $\mathrm{Cao}$, and Ying $\mathrm{Qu}$ contributed to statistical analysis and drafting of the manuscript. Zhaohui Wang and Wei Qi contributed to the strict revision of the manuscript and provided financial support. Hao Zang contributed to project design and strict revision of the manuscript. All of the authors read and agreed to the final manuscript.

\section{Acknowledgments}

The authors thank Michelle Kahmeyer-Gabbe, PhD, from Liwen Bianji, Edanz Editing, China (http://www.liwenbianji. $\mathrm{cn} / \mathrm{ac}$ ), for editing the English text of a draft of this manuscript. The work was supported by the Project of the Education Department of Jilin Province (JJKH20200487KJ) and the National Natural Science Foundation of China (81774393 and 81473794).

\section{References}

[1] M. Afzal, G. Gupta, I. Kazmi et al., “Anti-inflammatory and analgesic potential of a novel steroidal derivative from Bryophyllum pinnatum," Fitoterapia, vol. 83, no. 5, pp. 853-858, 2012.

[2] H. Uramoto, T. Ohno, and T. Ishihara, "Gastric mucosal protection induced by restraint and water-immersion stress in rats," Japanese Journal of Pharmacology, vol. 54, no. 3, pp. 287-298, 1990.

[3] M. Bardou, J.-P. Quenot, and A. Barkun, "Stress-related mucosal disease in the critically ill patient," Nature Reviews Gastroenterology \& Hepatology, vol. 12, no. 2, pp. 98-107, 2015.

[4] A. A. Monnig and J. E. Prittie, "A review of stress-related mucosal disease," Journal of Veterinary Emergency and Critical Care, vol. 21, no. 5, pp. 484-495, 2011.

[5] M. J. Spirt, "Stress-related mucosal disease: risk factors and prophylactic therapy," Clinical Therapeutics, vol. 26, no. 2, pp. 197-213, 2004.

[6] W. Alhazzani, F. Alenezi, R. Z. Jaeschke, P. Moayyedi, and D. J. Cook, "Proton pump inhibitors versus histamine 2 receptor antagonists for stress ulcer prophylaxis in critically ill patients," Critical Care Medicine, vol. 41, no. 3, pp. 693-705, 2013.

[7] Y. Liu, D. Li, and A. Wen, "Pharmacologic prophylaxis of stress ulcer in non-ICU patients: a systematic review and network meta-analysis of randomized controlled trials," Clinical Therapeutics, vol. 42, no. 3, pp. 488-498, 2020. 
[8] A. Ahmad, G. Gupta, M. Afzal, I. Kazmi, and F. Anwar, "Antiulcer and antioxidant activities of a new steroid from Morus alba," Life Sciences, vol. 92, no. 3, pp. 202-210, 2013.

[9] V. Prabhu and A. Shivani, "An overview of history, pathogenesis and treatment of perforated peptic ulcer disease with evaluation of prognostic scoring in adults," Annals of Medical and Health Sciences Research, vol. 4, no. 1, pp. 22-29, 2014.

[10] D. Das, D. Bandyopadhyay, M. Bhattacharjee, and R. K. Banerjee, "Hydroxyl radical is the major causative factor in stress-induced gastric ulceration," Free Radical Biology and Medicine, vol. 23, no. 1, pp. 8-18, 1997.

[11] H. Wang, W. J. Liu, G. M. Shen et al., "Neural mechanism of gastric motility regulation by electroacupuncture at RN12 and BL21: a paraventricular hypothalamic nucleus-dorsal vagal complex-vagus nerve-gastric channel pathway," World Journal Of Gastroenterology, vol. 21, no. 48, pp. 13480-13489, 2015.

[12] J. He, "Clinical observations on treatment of chronic atrophic gastritis by catgut embedding at combined Shu and $\mathrm{Mu}$ Points," Shanghai Journal of Acupuncture and Moxibustion, vol. 27 , no. 12 , pp. $8-10,2008$, in Chinese.

[13] H. Wang, G. M. Shen, W. J. Liu et al., "The neural mechanism by which the dorsal vagal complex mediates the regulation of the gastric motility by weishu (RN12) and zhongwan (BL21) stimulation," Journal of Evidence-Based Complementary \& Alternative Medicine, vol. 2013, Article ID 291764, 7 pages, 2013.

[14] P. Baiubon, P. Kunanusorn, P. Khonsung, N. Chiranthanut, A. Panthong, and C. Rujjanawate, "Gastroprotective activity of the rhizome ethanol extract of Zingiber simaoense Y. Y. Qian in rats," Journal of Ethnopharmacology, vol. 194, pp. 571-576, 2016.

[15] P. H. Guth, D. Aures, and G. Paulsen, "Topical aspirin plus $\mathrm{HCl}$ gastric lesions in the rat," Gastroenterology, vol. 76, no. 1, pp. 88-93, 1979.

[16] C.-Y. Chen, T.-L. Kuo, S.-Y. Sheu, and T.-F. Kuo, "Preventive effects of Chinese herb Chai-Hu-Gui-Zhi-Tang extract on water immersion restraint stress-induced acute gastric ulceration in rats," Journal of Veterinary Medical Science, vol. 72, no. 6, pp. 679-685, 2010.

[17] S. Marker, M. Krag, and M. H. Møller, "What's new with stress ulcer prophylaxis in the ICU?" Intensive Care Medicine, vol. 43, no. 8, pp. 1132-1134, 2017.

[18] M. Krag, A. Perner, A. Perner et al., "Prevalence and outcome of gastrointestinal bleeding and use of acid suppressants in acutely ill adult intensive care patients," Intensive Care Medicine, vol. 41, no. 5, pp. 833-845, 2015.

[19] R. MacLaren, P. M. Reynolds, and R. R. Allen, "Histamine-2 receptor antagonists vs proton pump inhibitors on gastrointestinal tract hemorrhage and infectious complications in the intensive care unit," JAMA Internal Medicine, vol. 174, no. 4, pp. 564-574, 2014.

[20] N. Zhang, G. Song, J. Chen et al., "Ameliorating effects and autonomic mechanisms of needle-less transcutaneous electrical stimulation at ST36 on stress-induced impairment in gastric slow waves," Journal of Gastroenterology and Hepatology, vol. 30, no. 11, pp. 1574-1581, 2015.

[21] Y. Zhao, C. Cui, X. Yu et al., "Electroacupuncture ameliorates abnormal defaecation and regulates corticotrophin-releasing factor in a rat model of stress," Acupuncture in Medicine, vol. 35, no. 2, pp. 114-121, 2017.

[22] J. Chen, D. W. Barrett, Y. He, and F. Gonzalez-Lima, “Anxiolytic-like behavioural effects of head electroacupuncture in rats susceptible to stress," Acupuncture in Medicine, vol. 34, no. 3, pp. 235-240, 2016.

[23] N. N. Yang, Y. Ye, Z. X. Tian et al., "Effects of electroacupuncture on the intestinal motility and local inflammation are modulated by acupoint selection and stimulation frequency in postoperative ileus mice," Neurogastroenterology \& Motility, vol. 32, no. 5, Article ID e13808, 2020.

[24] T. Y. Ho, H. Y. Lo, D. C. Chao et al., "Electroacupuncture improves trinitrobenzene sulfonic acid-induced colitis, evaluated by transcriptomic study," Journal of Evidence-Based Complementary \& Alternative Medicine, vol. 2014, Article ID 942196, 8 pages, 2014.

[25] H. Li, T. He, Q. Xu et al., "Acupuncture and regulation of gastrointestinal function," World Journal of Gastroenterology, vol. 21, no. 27, pp. 8304-8313, 2015.

[26] Y.-T. Jia, B. Ma, W. Wei et al., "Sustained activation of nuclear factor $-\kappa \mathrm{B}$ by reactive oxygen species is involved in the pathogenesis of stress-induced gastric damage in rats," Critical Care Medicine, vol. 35, no. 6, pp. 1582-1591, 2007.

[27] T. Brzozowski, S. Kwiecień, P. C. Konturek et al., "Comparison of nitric oxide-releasing NSAID and vitamin $\mathrm{C}$ with classic NSAID in healing of chronic gastric ulcers; involvement of reactive oxygen species," Medical Science Monitor, vol. 7, no. 4, pp. 592-599, 2001.

[28] R. F. C. Leitão, R. A. Ribeiro, E. A. L. Bellaguarda et al., "Role of nitric oxide on pathogenesis of 5-fluorouracil induced experimental oral mucositis in hamster," Cancer Chemotherapy And Pharmacology, vol. 59, no. 5, pp. 603-612, 2007.

[29] S. Kwiecień, T. Brzozowski, and S. J. Konturek, "Effects of reactive oxygen species action on gastric mucosa in various models of mucosal injury," Journal of Physiology and Pharmacology: An Official Journal of the Polish Physiological Society, vol. 53, no. 1, pp. 39-50, 2002.

[30] A. S. Tarnawski, "Cellular and molecular mechanisms of gastrointestinal ulcer healing," Digestive Diseases and Sciences, vol. 50, no. S1, pp. S24-S33, 2005.

[31] Y.-K. Yim, H. Lee, K.-E. Hong et al., "Electro-acupuncture at acupoint ST36 reduces inflammation and regulates immune activity in Collagen-Induced Arthritic Mice," Evidence-Based Complementary and Alternative Medicine, vol. 4, no. 1, pp. 51-57, 2007.

[32] H. Chen, X. Shao, L. Li et al., "Electroacupuncture serum inhibits TNF- $\alpha$-mediated chondrocyte inflammation via the Ras-Raf-MEK1/2-ERK1/2 signaling pathway," Molecular Medicine Reports, vol. 16, no. 5, pp. 5807-5814, 2017.

[33] J. Li, J. Li, R. Chen et al., "Targeting NF- $\kappa$ B and TNF- $\alpha$ activation by electroacupuncture to suppress collagen-induced rheumatoid arthritis in model rats," Alternative Therapies in Health and Medicine, vol. 21, no. 4, pp. 26-34, 2015.

[34] Z. Wang, T. Yi, M. Long, F. Ding, L. Ouyang, and Z. Chen, "Involvement of the negative feedback of IL-33 signaling in the anti-inflammatory effect of electro-acupuncture on allergic contact dermatitis via targeting MicroRNA-155 in mast cells," Inflammation, vol. 41, no. 3, pp. 859-869, 2018.

[35] Q.-M. Xue, H. Pan, L. Huang, and N. Li, "Effects of acupuncture at St25 on inflammatory mediators and nuclear factor $\kappa \mathrm{B}$ activation in a rat model of severe acute pancreatitis," Acupuncture in Medicine, vol. 33, no. 4, pp. 299-304, 2015.

[36] T.-h. Lin, J. Pajarinen, L. Lu et al., "NF- $\kappa$ B as a therapeutic target in inflammatory-associated bone diseases," Chromatin Proteins and Transcription Factors As Therapeutic Targets, vol. 107, pp. 117-154, 2017. 
[37] Q. Wang, R. Dziarski, C. J. Kirschning, M. Muzio, and D. Gupta, "Micrococci and peptidoglycan activate TLR2 $\longrightarrow \mathrm{MyD} 88 \longrightarrow \mathrm{IRAK} \longrightarrow \mathrm{TRAF} \longrightarrow \mathrm{NIK} \longrightarrow \mathrm{IKK} \longrightarrow$

NF- $\kappa$ B signal transduction pathway that induces transcription of interleukin-8," Infection and Immunity, vol. 69, no. 4, pp. 2270-2276, 2001.

[38] J. Segovia, A. Sabbah, V. Mgbemena et al., “TLR2/MyD88/NF$\kappa \mathrm{B}$ pathway, reactive oxygen species, potassium efflux activates NLRP3/ASC inflammasome during respiratory syncytial virus infection," PLoS One, vol. 7, no. 1, Article ID e29695, 2012.

[39] S. Akira, S. Uematsu, and O. Takeuchi, "Pathogen recognition and innate immunity," Cell, vol. 124, no. 4, pp. 783-801, 2006.

[40] M. Tsubaki, T. Takeda, T. Kino et al., "Mangiferin suppresses CIA by suppressing the expression of TNF- $\alpha$, IL-6, IL- $1 \beta$, and RANKL through inhibiting the activation of NF- $\kappa \mathrm{B}$ and ERK1/2," American Journal of Translational Research, vol. 7, no. 8, pp. 1371-1381, 2015.

[41] R. M. Vabulas, P. Ahmad-Nejad, S. Ghose, C. J. Kirschning, R. D. Issels, and H. Wagner, "HSP70 as endogenous stimulus of the Toll/interleukin-1 receptor signal pathway," Journal of Biological Chemistry, vol. 277, no. 17, pp. 15107-15112, 2002.

[42] K.-M. Lee, M. Yeo, J.-S. Choue et al., "Protective mechanism of epigallocatechin-3-gallate against Helicobacter pylori-induced gastric epithelial cytotoxicity via the blockage of TLR-4 signaling," Helicobacter, vol. 9, no. 6, pp. 632-642, 2004.

[43] R. Deva, P. Shankaranarayanan, R. Ciccoli, and S. Nigam, "Candida albicansInduces selectively transcriptional activation of cyclooxygenase-2 in HeLa cells: pivotal roles of toll-like receptors, p38 mitogen-activated protein kinase, and NF- $\kappa \mathrm{B}$," The Journal of Immunology, vol. 171, no. 6, pp. 3047-3055, 2003.

[44] E. Peterhans, "Oxidants and antioxidants in viral diseases: disease mechanisms and metabolic regulation," The Journal of Nutrition, vol. 127, no. 5, pp. 962S-965S, 1997.

[45] L. Lan, J. Tao, A. Chen et al., "Electroacupuncture exerts antiinflammatory effects in cerebral ischemia-reperfusion injured rats via suppression of the TLR4/NF- $\kappa \mathrm{B}$ pathway," International Journal of Molecular Medicine, vol. 31, no. 1, pp. 75-80, 2013. 